\title{
Investigating the Pollution Range in Groundwater in the Vicinity of a Tailings Disposal Site with Vertical Electrical Soundings
}

\author{
Robert Duda $^{1 *}$, Stanisław Mżyk ${ }^{2}$, Jan Farbisz ${ }^{2}$, Grzegorz Bania ${ }^{1}$ \\ ${ }^{1}$ AGH University of Science and Technology, Faculty of Geology, Geophysics and Environmental Protection, \\ Krakow, Poland \\ ${ }^{2}$ PBG Geophysical Exploration Ltd., Wrocław, Poland
}

Received: 10 September 2018

Accepted: 3 December 2018

\begin{abstract}
Various types of landfills pose a direct threat to groundwater. Polluted groundwater is characterized by significantly reduced electrical resistivity. Geophysical methods - in particular DC-resistivity methods - are sensitive to this physical parameter. Applying these methods can allow for a spatial assessment of the groundwater quality near the landfills. The key with that approach is to recognize the geoelectrical structure of an area prior to the existence of a landfill. This information will allow for a geoelectrical background, which would most likely be an image of the natural and uncontaminated study area. Subsequent measurements will be more effective due to the possibility of comparing the current state of the area to the original state. This paper presents an example of such a study. Here, the research area of interest was located in the vicinity of an inactive tailings disposal site. In order to assess the pollution of the groundwater, a vertical electrical sounding method was applied. The results of modern measurements were compared with those from the reinterpretation of the data obtained several decades ago. The selected geoelectrical method proved to be effective, allowing for the determination of the range of contaminated groundwater in regions that were not covered by traditional hydrogeological monitoring by a piezometer network. Repetition of vertical electrical sounding in the future will allow for tracking the displacement of pollution within the aquifer.
\end{abstract}

Keywords: groundwater pollution, tailings disposal site, geoelectrical method, vertical electrical sounding, waste disposal site

\section{Introduction}

After tailings disposal sites have been closed and waste has been deposited, groundwater in the vicinity

*e-mail: duda@agh.edu.pl of the area should be monitored for any environmental impacts or hazards. This approach also refers to mining tailings disposal sites, which create a serious hazard for the quality of groundwater and surface waters - especially when considering the presence of the accumulated, highly soluble mineral salts and the decadal influence of these disposal sites on groundwater and surface waters. 
Traditional hydrogeological monitoring starts with drilling boreholes where observation piezometers are installed. With these boreholes, water samples are systematically collected for chemical analyses. This method is costly, and while it gives point information it is acceptable only in small contamination sources located within areas of a simple geological structure. However, most mine waste disposal sites cover considerably large areas, sometimes ranging over a few $\mathrm{km}^{2}$. Moreover, these areas are sometimes located in proximity to complicated geological structures, where point recognition through piezometers does not suffice. Additionally, hydrogeological monitoring does not provide spatial information (3-D), which is needed for designing efficient remediation measures. In this situation, geoelectrical surveys allowing for spatial interpretation of the results would be a good tool for determining the range of the groundwater pollution zone surrounding the waste disposal sites.

Electrical resistivity is a physical parameter that may indicate the variability of permeable porous sediments. Sandy structures have favourable conditions for the expansion of polluted groundwater and manifest themselves as zones of elevated resistivity as compared to practically impermeable loams and clays, which have low resistivity values. Geoelectrical methods - especially DC resistivity methods - rely on the diversified electrical resistivity of different media and can easily facilitate and quickly recognize the geological structure, thus determining the condition of the nearsurface zone. These methods, including the electrical resistivity tomography (ERT) method, are frequently used for engineering and environmental surveys [1-6], especially those surveys of groundwater zones in the vicinity of waste disposal sites [7-17]. In particular, the vertical electrical sounding (VES) method is a promising approach that is discussed in this article. Despite the existence of the newer and more advanced ERT method, the VES method is still successfully used in the search for groundwater [18-21], characterization of its resources [22-25] and groundwater contamination surveys in the vicinity of waste disposal sites [26-30], thanks to its fast data collection and mapping of large areas.

Geoelectrical methods are advantageous in that they allow for the detection of aquifer zones saturated with salty water. Penetration of highly mineralized waters to an aquifer with fresh groundwater lowers the resultant electrical resistivity of this layer, which is proportional to the degree of water mineralization. Mixing of fresh groundwater with salty waters, e.g., leachates from waste disposal sites, causes lowering of an originally high resistivity value of sandy-gravel aquifers. Consequently, the image of an aquifer from the interpretation of geoelectrical surveys is similar to the resistivity values of loam layers. The comparison of low electrical resistivity values for loams and clays with the typically low resistivity values of permeable strata containing salty water creates a fundamental difficulty in the proper interpretation of pollutants present in groundwater and the delineation of their spatial 3-D range.

Another effect that can hinder the proper interpretation of geoelectrical surveys is the lowering of resistivity of impervious strata, i.e., clays and loams due to their long contact with salty waters. Through diffusion, chlorides and sulphates gradually migrate to micropores of these fine-grained structures. Consequently, loams may reach resistivity values that are characteristic of clays, which reach anomalously low resistivity values. For both these reasons, the identification of low-resistivity zones when considering the potential sources of groundwater pollution may be ambiguous. This ambiguity particularly applies to the situation when no archival geological profiles were available, i.e., before the source of pollution appeared; these profiles are an indispensable benchmark for geophysical interpretation. However, there is usually no such basic geological recognition with boreholes in the neighbourhood of old waste disposal sites, usually tens of years old.

Even with proper interpretation of the results from geoelectrical surveys of groundwater zone condition, these problems make the geoelectrical measurements of little use when correctly delineating the range of waste in groundwater. This study reports new approaches to solve these problems, especially in reference to the newly planned waste disposal sites and other potential sources of groundwater contamination. It was assumed that interpretation errors can be avoided by comparing basic geoelectrical surveys around the planned tailings disposal site (before the object was opened) on a broader scale with more recent measurements. The results of the surveys made before the disposal site became active are a natural geoelectrical background of the given area; with this baseline information, the geological structure of the site can be modelled. The comparison of recent measurements with basic geoelectrical surveys helped to clearly view the drop of electrical resistivity caused by the elevated salinity of groundwater. Consequently, the range of groundwater pollution during and after the tailings disposal (if the disposal site was not insulated from the bottom) should be correctly defined.

\section{Materials and Methods}

\section{Study Area}

The analysed case in this study was based on an inactive large post-flotation tailings disposal site in southwestern Poland (Fig. 1).

In the geological structure of the research area, the Neogene and Quaternary formations are of key importance. The Neogene formation is represented by Miocene and Pliocene deposits, while the Miocene is represented by sands, clays and brown coal layers, over which lay the Pliocene clays. The thickness of this 


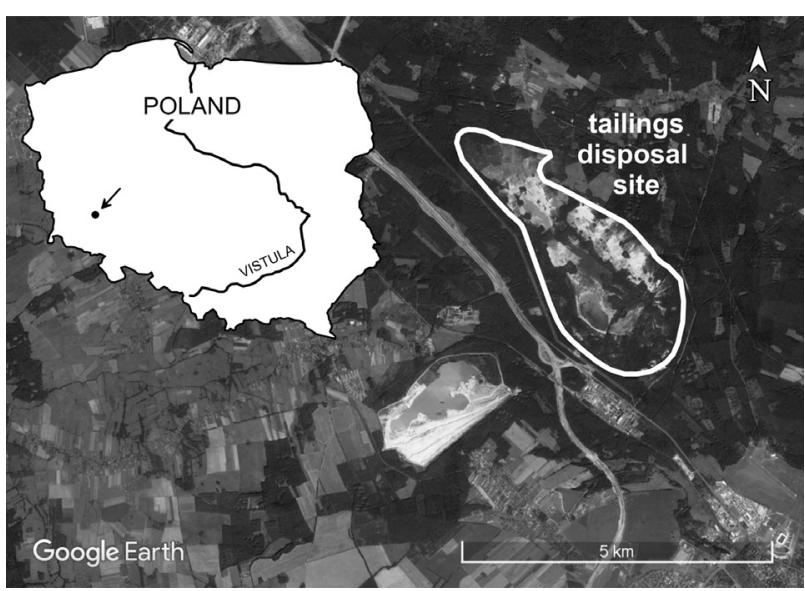

Fig. 1. Research area (source of aerial photo: Google Earth).

sediment complex is approximately $200 \mathrm{~m}$. Quaternary formations are mainly fluvioglacial sands with gravel and clay. The moraine clays are characterized by high lithological variability. These are sediments of silty, clayey, sandy and gravel fractions mixed together in various quantitative ratios. Above, below and within the clays, there are fluvioglacial sediments consisting of sands and gravels. Among these fluvioglacial sediments, there are pebbles and even boulders, which are usually made of granite. The composition of these sediments also includes loamy sands, silt, silty and sandy loam occurring in the form of lenses and small interbeddings. The thickness of the Quaternary sediments varies from 1 to $80 \mathrm{~m}$. The boundary of the glacier front overlap in this area caused the roof of the Pliocene clays to fold together with Quaternary clays and fluvioglacial sediments. Due to this process, there is large vertical and horizontal variability in the sediment stacking.

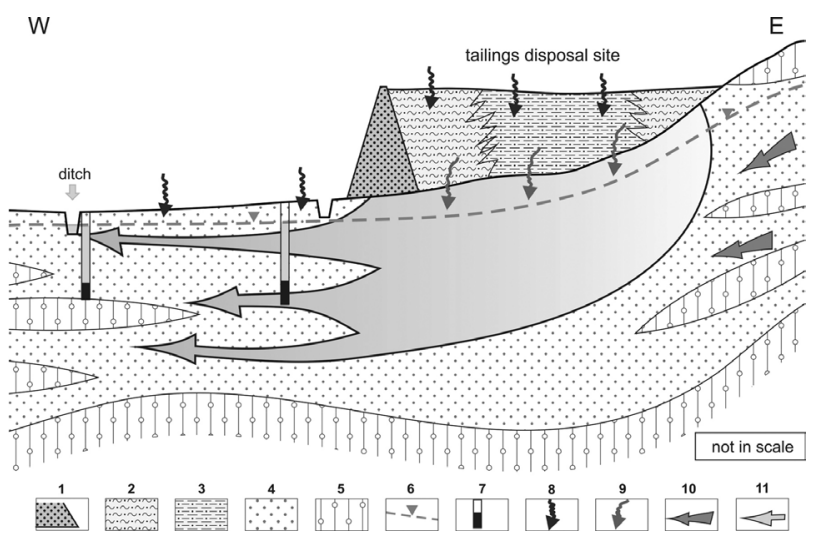

Fig. 2. Conceptual model of hydrogeological conditions and migration of pollutants from the tailings disposal site 1 - dam; 2 - coarse grained tailings; 3 - fine grained and silty tailings; 4 - mixed grained sands and gravel; 5 - low permeable sediment (boulder loam, silt); 6 - groundwater table; 7 - piezometer; 8 - infiltration of rain water; 9 - salty leakage from tailings; 10 - fresh groundwater inflow; 11 - contaminated groundwater outflow.
The tailings disposal site was running until 1980. It covered an area of $6.2 \mathrm{~km}^{2}$ (Fig. 1) and stored about 66 to 68 million $\mathrm{m}^{3}$ of post-flotation tailings. These tailings were mainly mineral waste, i.e., shales, sandstone and carbonate rocks comminuted in the process of ore enrichment. Quartz and carbonate minerals (calcite and dolomite) dominated in the waste material. There were also clay minerals, anhydrite, gypsum and sulphide ore minerals. Former settling reservoirs were not insulated from the bottom, and the post-flotation tailings poured out from the ore enrichment plant as a pulp. The hydro-transport of waste was based on high salinity mine brines. The high-salt leachate from the settling reservoir penetrated down the ground contaminating groundwater in an unconfined aquifer (Fig. 2). Part of the waste was coarse-grained; therefore, chlorides, sodium and sulphates were leached from the waste by rain waters and transported to the aquifer with the leachate even after the disposal processes had finished. The Pleistocene aquifer had a porous character as it was made of sands and gravel. Groundwater contaminated with chemical components from the leachate leaked from under the waste disposal site to the west, southwest and south (Fig. 3).

The specific type of contamination hazard in groundwater and surface waters in a disposal area is a result of using the highly saline waters in a mine $\left(\mathrm{SO}_{4}-\mathrm{Ca}\right.$ and $\left.\mathrm{Cl}-\mathrm{Na}\right)$ for the hydro-transport of waste. The mineralization of waters filling the porous space was about $17,000 \mathrm{mg} / \mathrm{l}$, whereas the concentration of chlorides, sodium, and sulphates were $6,600 \mathrm{mg} / \mathrm{l}$, $4,500 \mathrm{mg} / \mathrm{l}$ and 4,300 mg/l, respectively. These concentrations resulted in spreading waters containing high amounts of chlorides and sulphates into the nearby groundwater. Correlations between the electrical conductivity of water (important for geoelectrical surveys) and the concentrations of the main ions found in the water (chlorides, sulphates and sodium) in the groundwater near the foreground of the disposal site are presented in Fig. 4.

\section{Geoelectrical Survey}

Vertical electrical soundings (VES) with the use of a Wenner array were performed in the analysed area in 1961. The results of these measurements created a basis for the interpretation of a geoelectrical background: an image of the original (i.e., natural) hydrogeological medium prior to the construction of the tailings disposal site. The anomalous changes caused by the percolation of salty waters from the tailings to the Quaternary aquifer at the bottom of the disposal site were recorded because they caused a change in the geoelectrical image of the natural hydrogeological medium.

There were 160 reinterpreted archival VES curves and 80 performed new soundings within this research. To obtain a comparative material, measurements in 2015 were performed in places where the elevated salinity 


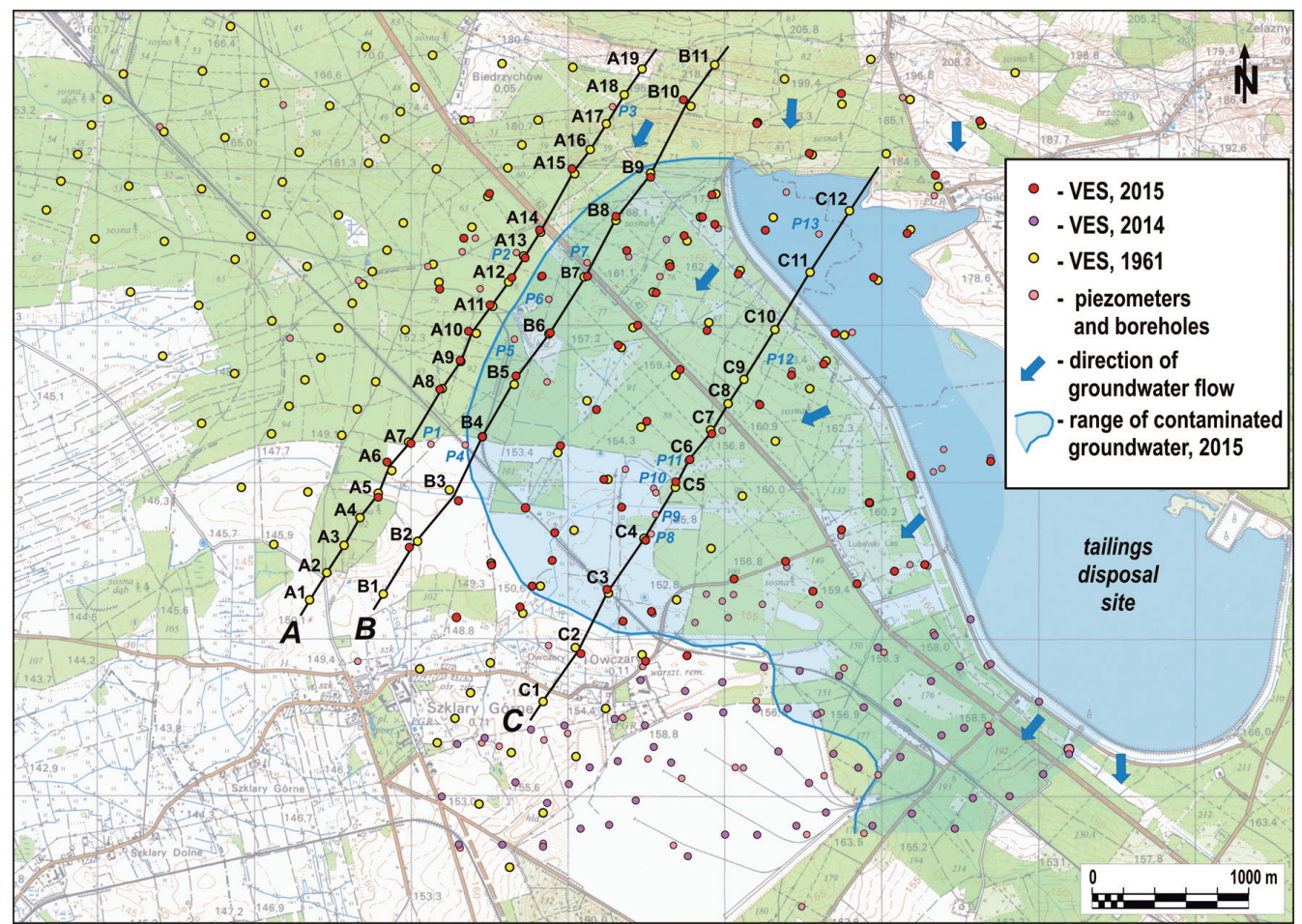

Fig. 3. Map showing placement of VES surveys and the interpreted impact range of waste disposal site (source of topographic map Geoportal.gov.pl).

of groundwater was expected. These places were selected on the basis of reinterpretation of the background VES data from 1961.

Geoelectrical layers differing in interpreted resistivity values were distinguished and ascribed according to proper lithology and water permeability conditions. The following identification criteria were assumed for sandy strata saturated with salty groundwater:

- Distinct lowering of resistivity of sandy strata recorded in the 2015 VES curves and repeated in locations where surveys were performed in 1961.

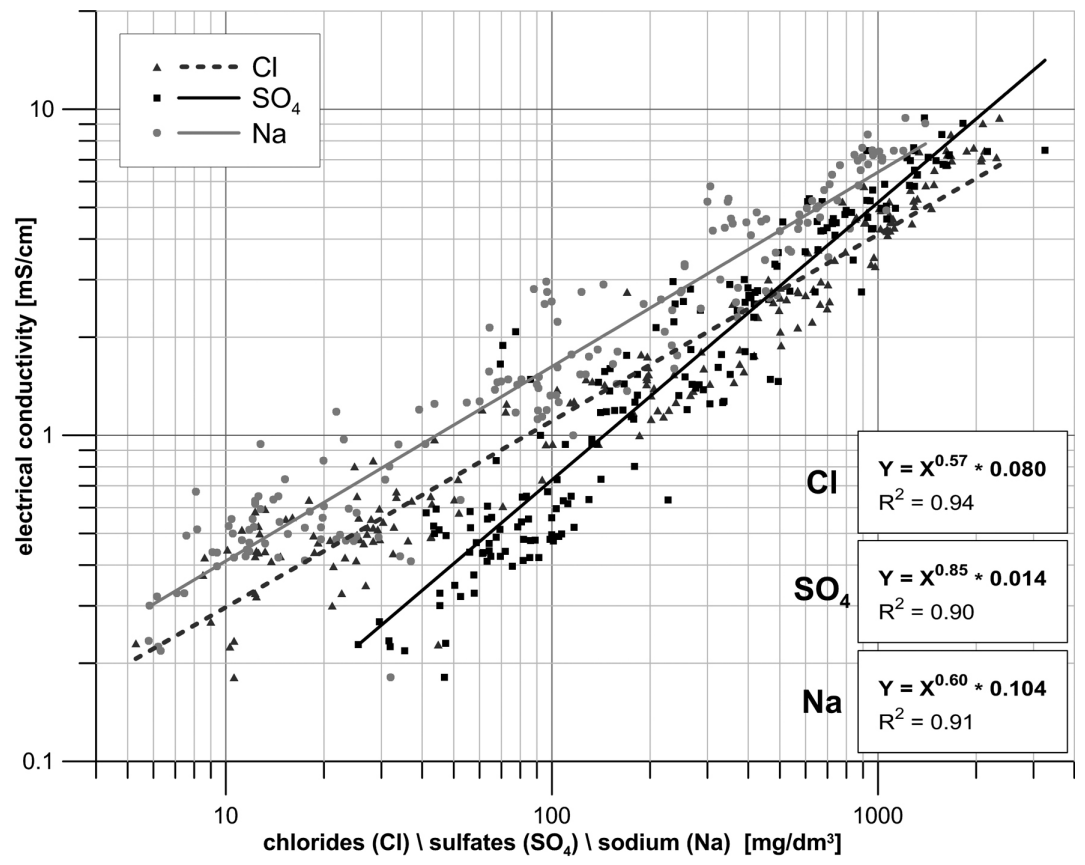

Fig. 4. Correlation of electrical conductivity and concentration of chlorides $(\mathrm{Cl})$, sodium $(\mathrm{Na})$ and sulfates $\left(\mathrm{SO}_{4}\right)$ in groundwater on the flotation tailings disposal site foreground. 


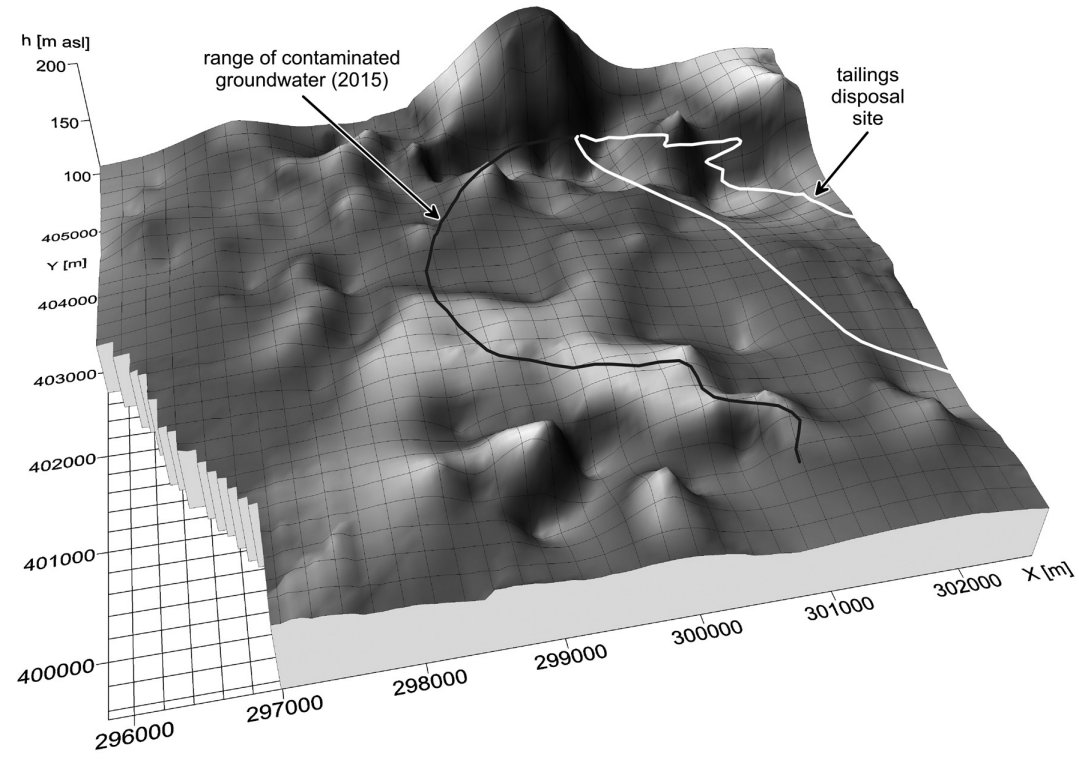

Fig. 5. Map of top surface of clays in the tailings disposal site vicinity.

- Comparison of boreholes and piezometers within geological profiles.

The new soundings were performed using a Schlumberger array for maximum current lines $\mathrm{AB}$
300-500 m, given a dependence on the thickness of the Quaternary strata at a depth of 50-70 m. Generally, VES surveys assumed that the high-resistivity complexes, i.e., permeable, sandy Quaternary strata were penetrated,
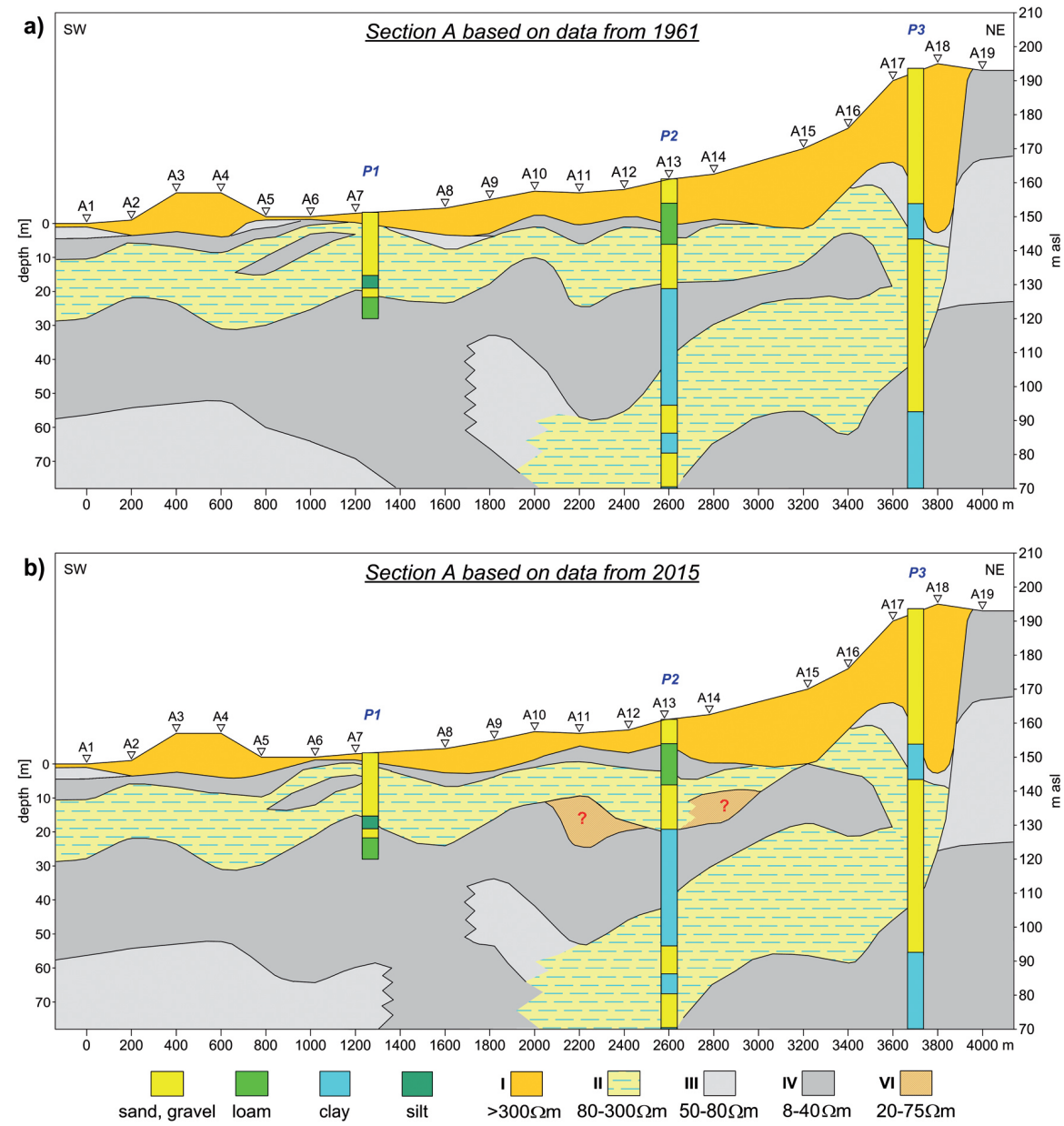

Fig. 6. Interpreted geoelectrical section A: a) archival data, b) recent data. 

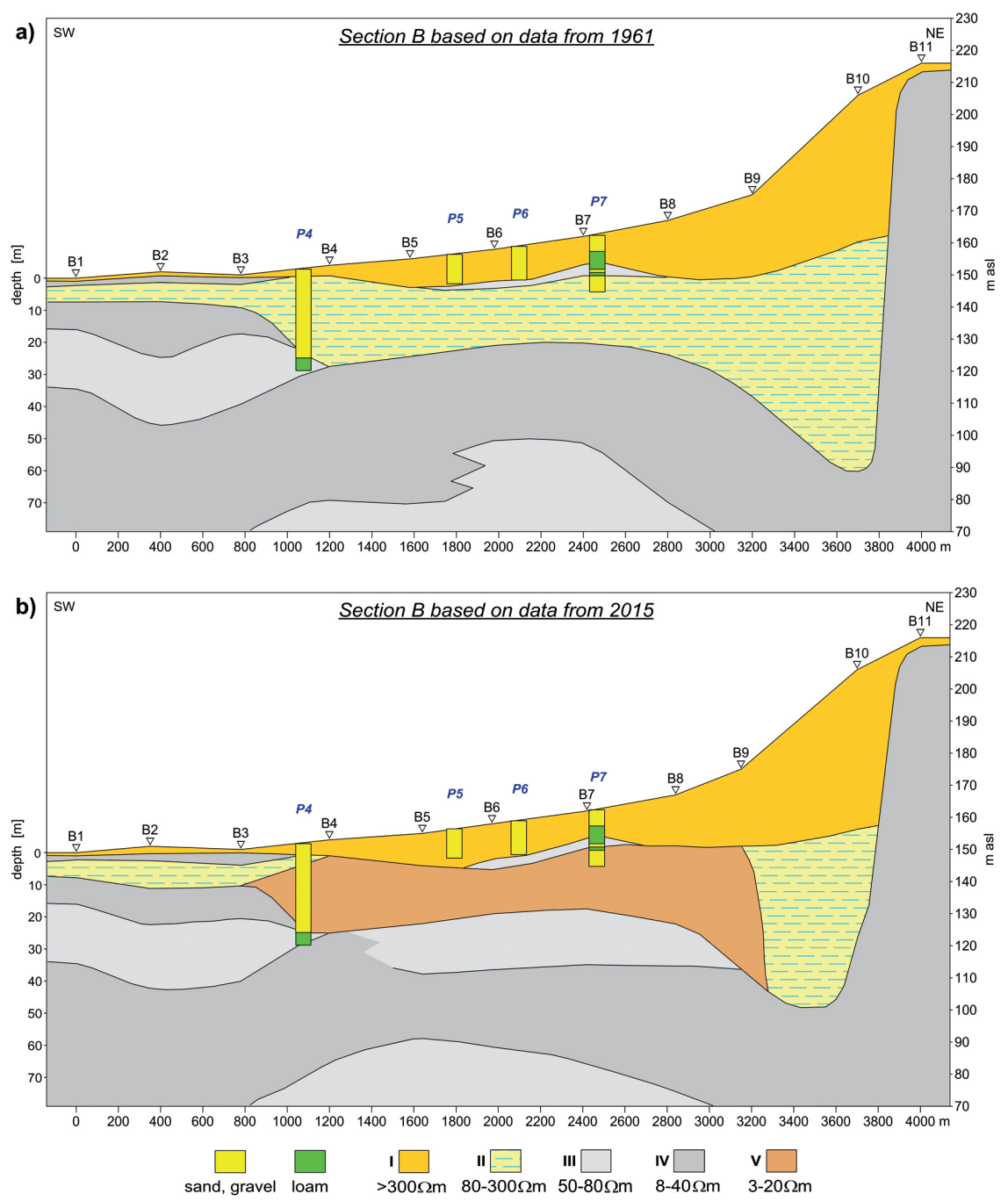

Fig. 7. Interpreted geoelectrical section B: a) archival data, b) recent data.

thus reaching the top of the low-resistivity impermeable Tertiary clays. The placement of VES stands was established with GPS, determining coordinates in a WGS84 system.

The parametric soundings on the boreholes in the neighbouring post-flotation tailings disposal site [26] created a basis for the estimated criteria used in the hydrogeological identification of the geoelectrical strata of selected sections (Figs 6-8):

I. Strata with an interpreted resistivity over $300 \Omega \mathrm{m}$ : sandy-gravel complexes with possible inter-bedding loams, deposited at the surface - anhydrous in the upper zone and water present locally in the bottom.

II. Strata with an interpreted resistivity of $80-300 \Omega \mathrm{m}$ : watered sand with gravel and pure sand.

III. Strata with an interpreted resistivity of 50-80 $\Omega \mathrm{m}$ : loamy-sandy complexes, with dominating loams, groundwater in possible sandy interlayers.

IV. Strata with an interpreted resistivity of 8-40 $\Omega \mathrm{m}$ : loams, clays and mudstones.

V. Strata with an interpreted resistivity of 3-20 $\Omega \mathrm{m}$ : permeable strata saturated with the salty waters anomalous drop of resistivity of sandy strata.
VI. Strata with an interpreted resistivity of 20-75 $\Omega \mathrm{m}-$ permeable strata within which the influence of salty waters was visible - considerable drop of resistivity of sandy strata.

Geoelectrical sections A-C (Figs 6-8) were quantitatively identified using the IPI2Win program [31]. Geoelectrical layers were correlated for sections when considering the similarity of the VES curves with the interpreted resistivity values. For improving the accuracy of interpretation, the series lines were incorporated with geological profiles of known boreholes and piezometers. Data about the depth intervals of installed filters in piezometers and concentrations of chlorides observed in samples collected in 2015 provided additional information to identify the sandy strata that contained waters of varying salinity.

\section{Results and Discussion}

In the DC resistivity method, the vertical resolution decreases with the increasing depth of recognition of the studied medium. In addition, the results of the inversion 

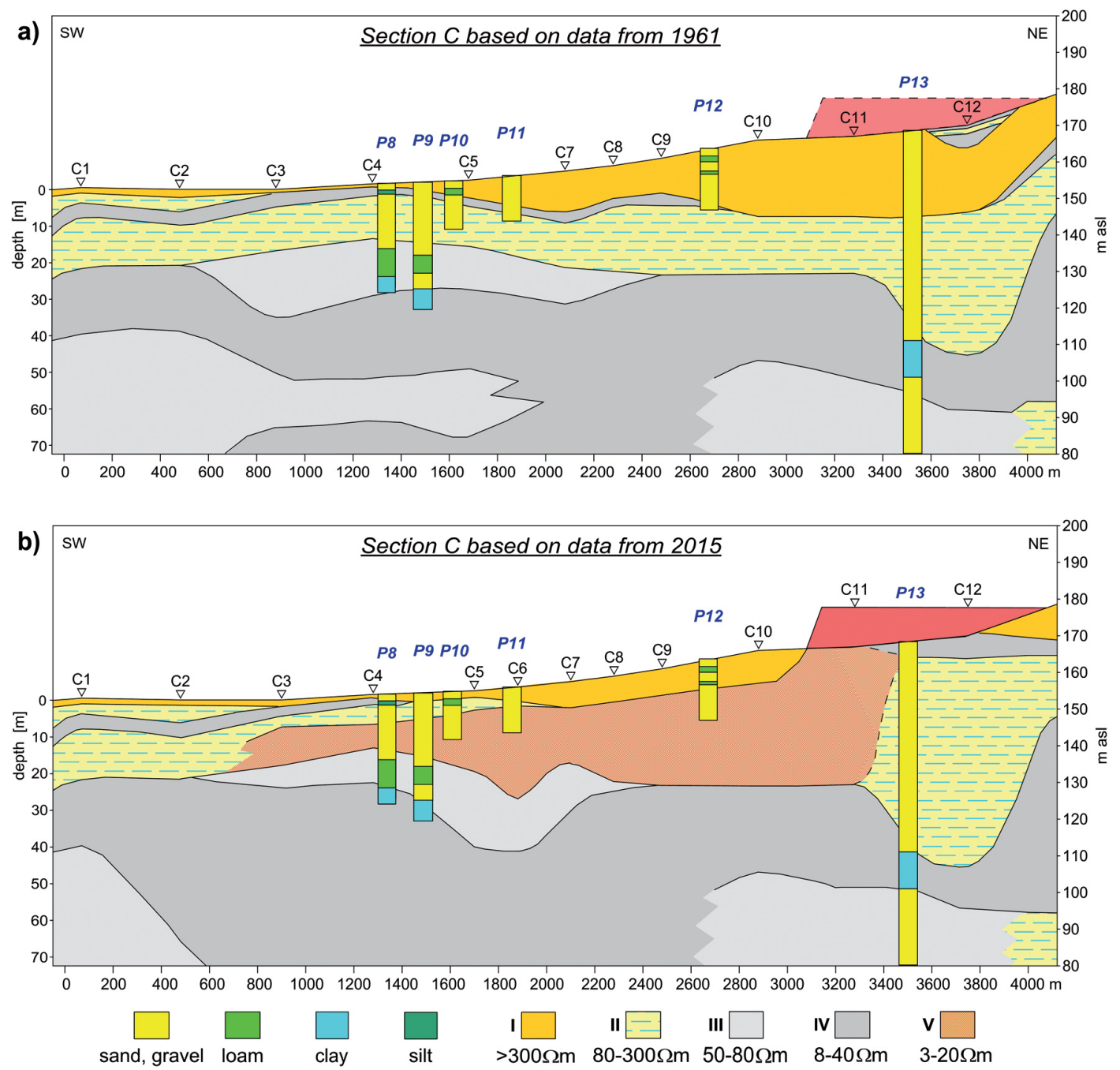

Fig. 8. Interpreted geoelectrical section C: a) archival data, b) recent data.

of VES data are ambiguous [32]. This ambiguity results in many equally correct (as in being compatible with field data) interpretations of geoelectrical models that differ in both properties and geometry. In addition, in the analysed case, the adjacent VES stands were located in the field at minimum distances of approximately $200 \mathrm{~m}$, which in turn affects the limited horizontal resolution. Therefore, the map presented in Fig. 5, as well as the geoelectrical sections discussed (Figs 6-8), are approximate and simply the most probable image of the hydrogeological medium investigated in this study.

The weakly permeable Pleistocene clays play a crucial role for the conditions where contamination from the disposal site can migrate into groundwater. The importance of the similar clay layer is also noted in the nearby tailings disposal site [26] as well as other locations, such as when in proximity to steelwork near Krakow, Poland, where heaps and tailings ponds are present [16]. A map from the study area representing the surface of the roof of the clays was obtained with the inversion of the VES data (Fig. 5). As can be seen in this figure, the roof part of the weakly permeable strata is strongly folded, elevated and deeply cutting in erosion structures due to glaciotectonics.

Owing to the big number of VES measurements (240 stands), there were more than 20 interpreted geoelectrical sections. Only selected sections (locations in Fig. 3) were presented in this paper, showing how a given section can change when under the influence of leachate from the tailings disposal site, even decades after the disposal site was terminated (Figs 6-8). The sections representing deposition of interpreted geoelectrical strata were paired. The section based on the inversion of archival data is given in (a), and the recent section in (b). Colours and signature marks were used to highlight strata and geoelectrical complexes identified with sandy strata: water-free strata, strata containing unpolluted groundwater and strata containing contaminated groundwater.

The thickness of the Quaternary sediments in the analysed area varies from a few to over $70 \mathrm{~m}$ (Figs 6-8). The Quaternary sediments in that area lithologically differ in both vertical perspective and horizontal extent. The sandy-gravel sediments appear as discontinuous strata or lenses between weakly permeable strata (loam) 
and impermeable strata (clay). The highest thickness of sandy-gravel sediments was observed in the sounding stand B10 (Fig. 7), which was performed in an elevated area. In the remaining part of the area, sandy-gravel sediments of the Quaternary aquifer are 30-40 m thick.

The zone of the impact of the former waste disposal site on groundwater, determined from the surveys in 2015, extends to the southwestern at a distance of about $2.5 \mathrm{~km}$ from the object (Fig. 3). The analysis of the obtained results in those surveys in relation to the analysis of hydrogeological conditions shows that the inflow of clean groundwater from the elevated areas, located in the northern part of the analysed area, efficiently limits the westward migration of salty waters. The contamination of groundwater practically does not exceed section line A (Fig. 3). The comparison of section A for archival data (Fig. 6a) with the section for recent data (Fig. 6b) reveals that these two datasets do not substantially differ. The only exception is in the sounding stands A11 and A14, in the area of a permeable sandy complex, the zones of lowered interpreted resistivity were indicated with question marks. These zones can be attributed to the influence of contaminated groundwater spreading within the aquifer. On the other hand, in sections $\mathrm{B}$ and $\mathrm{C}$ (Figs 7 and 8), there are notable differences when comparing archival data (panel "a") and recent data (panel "b"). The interpreted zones of contaminated groundwater for recent data (Figs $7 \mathrm{~b}$ and $8 \mathrm{~b}$ ) cover considerably large fragments of the aquifer.

The deeper, contaminated parts of the groundwater stream that flow under loams reach the more distant drainage bases (Figs 7 and 8). In that case, the salinization of groundwater may progress to the southwestern direction. Anomalously low values of the interpreted resistivity of aquifers (5-20 $\Omega \mathrm{m})$ and considerable drops of apparent resistivity in VES curves in stands where measurements were performed in 2015 (as compared to the 1961 background), were assumed to be a result of this disengagement. Such resistivity values are characteristic of strata saturated with contaminated groundwater [cf. e.g., 9, 13, 16, 26-28]. This applies to sandy-gravel permeable strata and also loams and clays. In loams, there is a slow migration of salt to pore space, as is frequently observed with diffusion, due to the long contact with strongly polluted (i.e., mineralized) groundwater. Similar problems occur in the case of saltwater intrusion in coastal areas, which is a result of overexploitation of groundwater resources [33-36]. Consequently, the electrical resistivity of loams of standard values $30-40 \Omega \mathrm{m}$ may reach lower values that are typical of clays. Therefore, differentiating between low-resistivity zones of loams and clays in certain geoelectrical sections may be ambiguous.

As mentioned earlier, on the basis of VES data from 1961, a geoelectrical image of the studied area was obtained from the time preceding the existence of a tailings disposal site. The research results from 2015 suggest a significant change in the study area that is indicative of the spread of contaminated waters within the aquifer. The results of the analyses presented in this article can be used as a basis for further research on geoelectrical monitoring. In addition, future monitoring work can focus on a more local scale. Based on the obtained cross-sections (Figs 6-8) and map of the contaminated water range (Fig. 3), it is possible to conduct monitoring only in selected, endangered parts of the study area, e.g., the border between fresh and contaminated groundwater. With this more localized approach, it is also possible to select interesting installation sites for new piezometers for hydrogeological monitoring purposes. Nevertheless, combined geophysical and hydrogeological studies are an effective tool for assessing the state of groundwater contamination. Notably, there is similar research regarding the nearby Żelazny Most tailings disposal site. In that work, approximately 10 years of geophysical and hydrogeological monitoring was applied to an area with a very similar geological structure to the one discussed in this study. Vertical electrical sounding together with other geophysical methods proved to be effective in mapping polluted groundwater within post-glacial formations filled with sand and gravel [26].

\section{Conclusions}

In this research, geophysical analyses covering 80 modern VES surveys and reinterpretation of 160 archival soundings, provided a detailed recognition of the geological structure of the tailings disposal site area to a depth of approximately $70 \mathrm{~m}$ and gave current information on the extent of contamination that migrated from the disposal site to areas where traditional groundwater monitoring is unavailable.

Through comparing recent VES data to the archived data, this study achieved high efficiency of performed geoelectrical surveys to delineate the present range of contaminated groundwater. The interpretation of the archived soundings data determined the geological structure of the study area in its original, uncontaminated state. Significant changes were noted when comparing modern VES data with the archived data. In this comparison, there was a drop in interpreted resistivity values, which was evoked by the changing salinity of groundwater. The drop of resistivity values suggests increased contamination. When applying the methodology described here to future studies, it will be possible to observe an increase in interpreted resistivity values. This increase may indicate the progress of ongoing natural attenuation of contamination or the effectiveness of possible remediation activities.

This study shows that in order to avoid errors in the interpretation of the results of geoelectrical surveys, it is important to incorporate a broader range of basic measurements performed in the vicinity of the planned waste disposal site prior to its construction. The implementation of these data into a model of 
the geoelectrical-geological structure of the area will improve its accuracy and resolution. These data also serve as the geoelectrical background of the area. The basic survey preceding the disposal of waste, followed by repeated measurements after operation of the disposal site has been performed, will accurately differentiate between the range of polluted groundwater in a sandy aquifer from loamy and clayey strata that do not change their position in the bedrock. These results should improve the initiatives aimed at correctly locating activities to reduce groundwater contamination.

Tracing the further advancement of the flow of salty waters requires systematic geoelectrical monitoring in the form of repeated surveys in the same place over a few years. Such types of monitoring approaches are widely applied to similar environmental problems [34$35,37-38]$.

\section{Acknowledgements}

Our research was financially supported by AGH University of Science and Technology grant No. 11.11.140.797.

\section{Conflict of Interest}

The authors declare no conflict of interest.

\section{References}

1. DAHLIN T., 2D resistivity surveying for environmental and engineering applications. First Break, 14 (1137), 1996.

2. SAINATO C.M., LOSINNO B.N., MALLEVILLE H.J., Assessment of contamination by intensive cattle activity through electrical resistivity tomography. Journal of Applied Geophysics, 76, 82, 2012.

3. SECHMAN H., MOŚCICKI W.J., DZIENIEWICZ M., Pollution of near-surface zone in the vicinity of gas wells. Geoderma, 197-198, 193, 2013.

4. ŻUREK A.J., WITCZAK S., DULIŃSKI M., WACHNIEW P., RÓŻANSKI K., KANIA J., POSTAWA A., KARCZEWSKI J., MOŚCICKI W.J., Quantification of anthropogenic impact on groundwater-dependent terrestrial ecosystem using geochemical and isotope tools combined with 3-D flow and transport modelling. Hydrology and Earth System Sciences, 19 (2), 1015, 2015.

5. ABBAS M., JARDANI A., MACHOUR N., DUPONT J.P., Geophysical and geochemical characterisation of a site impacted by hydrocarbon contamination undergoing biodegradation. Near Surface Geophysics, 16 (2), 1, 2018.

6. MUSZAGIA A.D., WIDODO W., SISWOYO A.R.F., YUDHISTIKA A., DAVY N., WARSA W., Groundwater mapping survey using geoelectrical method in Pasirlayung, Bandung, West Java, Indonesia. AIP Conference Proceedings, 2018.

7. BERNSTONE C., DAHLIN T., OHLSSON T., HOGLAND H., DC-resistivity mapping of internal landfill structures, Two pre-excavation surveys. Environmental Geology, 39 (3-4), 360, 2000.
8. MEADS L.N., BENTLEY L.R., MENDOZA C.A., Application of electrical resistivity imaging to the development of a geologic model for a proposed Edmonton landfill site. Canadian Geotechnical Journal, 40 (3), 551, 2003.

9. MARTINEZ-PAGAN P., CANO A.F., ARACIL E., AROCENA J.M., Electrical resistivity imaging revealed the spatial properties of mine tailing ponds in the Sierra Minera of southeast Spain. Journal of Environmental \& Engineering Geophysics, 14 (2), 63, 2009.

10. CLEMENT R., DESClOITRES M., GUNTHER T., OXARANGO L., MORRA C., LAURENT J.-P., GOURC J.P., Improvement of electrical resistivity tomography for leachate injection monitoring. Waste management, 30 (3), 452, 2010.

11. DAHLIN T., ROSQVIST H., LEROUX V., Resistivity-IP mapping for landfill applications. First Break, 28 (8), 101, 2010.

12. PLACENCIA-GÓMEZ E., PARVIAINEN A., HOKKANEN T., LOUKOLA-RUSKEENIEMI K., Integrated geophysical and geochemical study on AMD generation at the Haveri Au-Cu mine tailings, SW Finland. Environmental Earth Sciences, 61 (7), 1435, 2010.

13. MARTÍN-CRESPO T., MARTIIN-VELÁZQUEZ S., GÓMEZ-ORTIZ D., DE IGNACIO-SAN JOSÉ C., LILLO-RAMOS J., A Geochemical and geophysical characterization ofsulfide mine ponds at the Iberian Pyrite Belt (Spain). Water, Air,\& Soil Pollution, 217 (1-4), 387, 2011.

14. DE CARLO L., PERRI M.T., CAPUTO M.C., DEIANA R., VURRO M., CASSIANI G., Characterization of a dismissed landfill via electrical resistivity tomography and mise-à-la-masse method. Journal of Applied Geophysics 98, 1, 2013.

15. PIERWOŁA J., Investigation of soil contamination using resistivity and induced polarization methods. Polish Journal of Environmental Studies, 22 (6), 1781, 2013.

16. BANIA G., ĆWIKLIK M., Study of a subsurface zone condition in the vicinity of an industrial waste heap with ERT method. 77th EAGE Conference and Exhibition 2015, Madrid, Spain, EAGE Publications BV, Netherlands, 2015.

17. GAËL D., TANGUY R., NICOLAS M., NGUYEN F., Assessment of multiple geophysical techniques for the characterization of municipal waste deposit sites. Journal of Applied Geophysics, 145, 74, 2017.

18. NEJAD H.T., MUMIPOUR M., KABOLI R., NAJIB O.A., Vertical electrical sounding (VES) resistivity survey technique to explore groundwater in an arid region, southeast Iran. Journal of Applied Sciences, 11, 3765, 2011.

19. DANIEL A., LOUIS O., EMMANUEL C., KINGSLEY O. Delineation of potential groundwater zones using geoelectrical sounding data at Awka in Anambra State, south-eastern Nigeria. European Journal of Biotechnology and Bioscience, 3 (1), 01, 2015.

20. FARID H.U., MAHMOOD-KHAN Z., ALI A., MUBEEN M., ANJUM M.N., Site-specific aquifer characterization and identification of potential groundwater areas in Pakistan. Polish Journal of Environmental Studies, 26 (1), 17, 2017.

21. LEITE D.N., BORTOLOZO C., PORSANI J.L., COUTO JR., M.A., REALPE J., MONTEIRO DOS SANTOS F.A., RANGEL R., HAMADA L.R., SIFONTES R.V., SEREJO G., STANGARI M.C., Geoelectrical characterization with 1D VES/TDEM joint inversion in Urupês-SP region, 
Paraná Basin: Applications to hydrogeology. Journal of Applied Geophysics, 151, 205, 2018.

22. ASFAHANI J., Groundwater potential estimation using vertical electrical sounding measurements in the semi-arid Khanasser Valley region, Syria. Hydrological Sciences Journal, 58 (2), 468, 2013.

23. OKONKWO A.C., EZEH C.C., Aquifer hydraulics and delineation of groundwater quality zones using electrical resistivity method at Oduma and environs in Enugu State, southeastern Nigeria. International Research Journal of Geology and Mining, 3 (1), 31, 2013.

24. SRINIVASAN K., POONGOTHAI S., CHIDAMBARAM S., Identification of groundwater potential zone by using GIS and electrical resistivity techniques in and around the Wellington Reservoir, Cuddalore District, Tamilnadu, India. European Scientific Journal, 9 (17), 312, 2013.

25. FARID H.U., BAKHSH A., Use of vertical electrical sounding (VES) techniques to explore the groundwater potential. Asian Journal of Science and Technology, 6 (1), 915, 2015.

26. LASOCKI S., ANTONIUK J., MOŚCICKI W.J., Environmental protection problems in the vicinity of the Żelazny Most flotation wastes depository in Poland. Journal of Environmental Science and Health, Part A, 38 (8), 1435, 2003.

27. AKANKPO A.O., IGBOEKWE M.U., Monitoring groundwater contamination using surface electrical resistivity and geochemical methods. Journal of Water Resource and Protection, 3, 318, 2011.

28. OGUNGBE A.S., ONORI E.O., OLAOYE M.A., Application of electrical resistivity techniques in the investigation of groundwater contamination: A case study of Ile-Epo Dumpsite, Lagos, Nigeria. International Journal of Geometrics and Geosciences, 3 (1), 30, 2012.

29. PUTIŠKA R., KUŠNIRÁK D., DOSTÁL I., VYBÍRAL V., PAŠTEKA R., PAPČO J., Landfill geophysical imaging - Babica Landfill case study. Near Surface Geoscience $2016-22^{\text {nd }}$ European Meeting of Environmental and Engineering Geophysics, 2016.
30. ABU HEEN Z.H., Use of electrical resistivity methods (2-D and VES) in proposed landfill site investigation Acase study of Al Fukhari Landfill, southeastern Gaza Strip, Palestine. Journal of Environment and Earth Science, 7 (3), 119, 2017.

31. BOBACHEV, A., Resistivity Sounding Interpretation IPI2Win. Moscow State University, 2010. (geophys.geol. msu.ru/ipi2win.htm).

32. LOKE M.H., Tutorial: 2-D and 3-D electrical imaging surveys. Geotomo Software. Malaysia, 2016. (www. geotomosoft.com).

33. ABDUL NASSIR S.S., LOKE M.H., LEE C.Y., NAWAWI M., Salt-water intrusion mapping by geoelectrical imaging surveys. Geophysical Prospecting, 48 (4), 647, 2000.

34. FRANCO R. DE, BIELLA G., TOSI L., TEATINI P., LOZEJ A., CHIOZZOTTO B., GIADA M., RIZZETTO F., CLAUDE C., MAYER A., BASSAN V., GASPARETTOSTORI G., Monitoring the saltwater intrusion by time lapse electrical resistivity tomography, the Chioggia test site (Venice Lagoon, Italy). Journal of Applied Geophysics, 69 (3-4), 117, 2009.

35. ULUSOY İ., DAHLIN T., BERGMAN B., Time-lapse electrical resistivity tomography of a water infiltration test on Johannishus Esker, Sweden. Hydrogeology Journal, 23 (3), 551, 2015.

36. MARTÍNEZ-MORENO F.J., MONTEIRO-SANTOS, F.A., BERNARDO I., FARZAMIAN M., NASCIMENTO C., FERNANDES J., CASAL B., RIBEIRO J., Identifying seawater intrusion in coastal areas by means of 1D and quasi-2D joint inversion of TDEM and VES data. Journal of Hydrology, 552, 609, 2017.

37. CLÉMENT, R., OXARANGO, L., DESCLOITRES, M., Contribution of 3-D time-lapse ERT to the study of leachate recirculation in a landfill. Waste management, 31 (3), 457, 2011.

38. PARK S., YI M., KIM J., SHIN S.W., Electrical resistivity imaging (ERI) monitoring for groundwater contamination in an uncontrolled landfill, South Korea. Journal of Applied Geophysics, 135, 1, 2016. 